\title{
Inferior Vesical Artery
}

National Cancer Institute

\section{Source}

National Cancer Institute. Inferior Vesical Artery. NCI Thesaurus. Code C52685.

A blood vessel arising from the anterior side of the internal iliac artery that supplies the base of the bladder, prostate gland and seminal vesicles. 